Jouke Post*

DOI: 10.18290/pepsi-2019-0004

\title{
Parsons Revisited: A Search for Adaptive Matching Instruments
}

\section{ABSTRACT}

The purpose of this article is to explore innovative and adaptive ways of matching people with jobs in the context of a Dutch policy initiative aimed at the skills mismatch in the region of Amsterdam. This is an important and urgent issue because of the challenges of the future labor market, in which technological disruption and socio-economic forces affect the content and conditions of jobs and occupations. Powered by digital technology and data-driven approaches it is possible to design 'fine-grained' matching systems based on skills or competences. The article combines an exploration of occupational taxonomies, skills frameworks and good practices of these skills-based applications with a theoretical discussion on the relevance and adaptations of Person-Environment Fit and matching theories. The article shows that these new forms of innovative, adaptive and fluid matching have benefits for policy-makers, employers and jobseekers alike. In the discussion section some critical remarks are made on the matching theory and its application in contemporary instruments and tools.

KEYWORDS: career guidance, matching, competences, skills policy, skills, career theory.

* Correspondence regarding the paper should be sent to: Jouke Post, School of Human Resources at Saxion University of Applied Sciences in Deventer (Netherlands), e-mail: j.post@saxion.nl 
In this article the possibilities of a skills-based application of matching people with jobs are explored in the context of a policy initiative in the region of Amsterdam called 'The House of Skills'. According to Bauman we live in liquid times (Bauman, 2000; Sultana, 2018). In his opinion 'solid modernity' has evolved into 'liquid modernity', which he describes as a condition of mobility and change in relationships, identity and work. Work must therefore be regarded in a different way: 'work can no longer offer the secure axis around which to wrap and fix self-definitions, identities and life-projects' (Bauman, 2000, p. 139). It will be argued that these new conditions of 'liquidity' and 'fluidity' transform the way jobs, occupations and careers are being conceived in at least two ways. Firstly, the environment of work and career is becoming more dynamic, relational and decentralized (Grant \& Parker, 2009). A vast amount of jobs becomes less scripted and will leave space for discretion, proactive behavior and individualization regarding the content and arrangements of these jobs (Dierdorff \& Morgeson, 2007). Next to this and powered by a data-driven approach of new digital matching technologies and tools, the emphasis at the demand side of the labour market will change from occupations to tasks and skills (World Economic Forum, 2019). Consequently, skills will increasingly prove to be a relevant element in matching people with jobs and turn out to be a suitable proxy for advanced and tailor-made career guidance, enabling job-seekers to discover effective and appropriate reskilling pathways and job opportunities (European Commission, 2014).

Both shifts change the relevance and applications of the traditional and well-tried Person-Environment Fit or matching theory in contemporary careers practice. In the transitional labour market (Schmid, 1998) of the first quarter of the 21th century new and digital forms of assessment and matching will emerge, in which the classical person-environment-fit becomes less static and fixed and increasingly dynamic and adaptive. These new approaches reflect the dynamism in both the work environment and the in- 
dividual (Frese \& Fay, 2001). Furthermore, they have the promise of facilitating the jobseeker's autonomy and possibilities to steer and manage his career (Sylva, Mol, Den Hartog, \& Dorenbosch, 2019; European Centre for the Development of Vocational Training [Cedefop], 2016).

\section{MATCHING THEORY AND ADAPTIVE TOOLS AND PRACTICES}

The scientific origins of the P-E fit approach can be traced to Frank Parsons theory of matching, which is considered one of the milestones of career theory and practice (Parsons, 1909). Fit is seen as a key and almost self-evident determinant of job and career satisfaction: congruence between a person's characteristics and his or her work environment leads to greater satisfaction, success and persistence (Su, Murdoch, \& Rounds, 2015). Empirical fit studies have shown that correspondence between an individual and a specific aspect of the environment (e.g. job, organization, supervisor) predicts many important outcomes, such as satisfaction, strain, performance, and turnover, among others (Kristof-Brown, Zimmerman, \& Johnson, 2005). A strong quantitative orientation in P-E fit studies has stimulated the development of robust and very precise quantitative measures of the various dimensions of fit (Kristof-Brownet al., 2005).

The matching theory and its various operationalizations have been criticized over and over, mostly in relation to its supposed simplicity, reductionism and conceptual fallacies (Savickas, 1997; Maree, 2017; Edwards, 2008). Jansen and Shipp (2018) argue that the fragmented nature of the measured and (mostly) quantitative P-E fit also fails to capture how people experience and conceive their fit in a more holistic sense (i.e., where multiple aspects of fit interact or combine to form an overall subjective assessment). Osipow and Fitzgerald (1996) underline the failure of the theory to address the issue of change in environments and individuals. 
Matching assumes a degree of stability in the labour market that is no longer the reality.

Despite these theoretical limitations the practical relevance of the concept of P-E fit and matching is still widespread and enormously influential (Bimrose (n.d.); Moore, Gunz, \& Hall, 2007). Career professionals and other professionals in the area of welfare and work are inclined to conceptualize their methods, instruments and guidance around the concept of fit or matching (Inkson, Dries, \& Arnold, 2015; Hartung, 2005). Many career- and Human Resource Management-programs, websites and virtual technologies are based on the systematic comparison and assessment of persons and jobs (Reid, 2016; Mittendorff, Faber \& Staman, 2017). The claim in this article will be that this practical relevance will continue and turn out to be persistent, but in a different and more adaptive way. There are two main causes for the significant change in the way the matching of people with work in the first quarter of the 21st century is taking place.

Firstly, there is a profound transformation in the way labour (occupations, jobs) and, consequently, people (qualities, skills) are being conceived. The fixed and more broad ways of looking at occupations and jobs are being replaced by fragmented, fluid and flexible ways of thinking about work. Jobs and occupations are being broken down in more specific and detailed units, tasks in particular (Hall \& Las Heiras, 2007).

A second cause can be found in the proliferation of job (re)design tools like 'job crafting', 'job carving' and 'job engineering', where jobs are being moulded into individualized and personalized arrangements (Sanders, 2016). The selection and adaptation of tasks and conditions of the job are essential in this process. These tools create a more dynamic fit between the crafting person and his or her work and tasks. They can be seen as forms of adaptive and proactive matching and therefore as a direct reflection of the transitional and dynamic characteristics of the modern labour market, with its increasing emphasis on career adaptability and agency. 
It is obvious that these frames of adaptive, personalized and subjective matching have a direct connection to contemporary career guidance and counseling theory, and to the (diagnostic) competences and daily reality of career practitioners (NICE, 2016). The concept of career adaptability, accentuating the agentic and individualistic nature of the modern career (De Vos \& Van der Heijden, 2015), can be applied professionally in concrete tools and systems integrating a more dynamic and malleable conception of the matching process.

\section{HOUSE OF SKILLS}

The House of Skills initiative in the region of Amsterdam (Netherlands) is an example of the quest for such tools. In this network of organizations, the local and regional government, together with employers, trade unions, career guidance institutes, Public Employment Services, higher and vocational education and private institutions aim to develop innovative ways of 'meeting the skills mismatch' on a regional scale. Because of the more urgent threat of obsolete skills for workers in this segment the focus of House of Skills is on the middle segment of the labour market.

Crucial element of this innovation is the centrality of the concept of 'skills' in the variety of projects and pilots that are to be executed during the next years. Skills (or competences) are defined according to the OECD-definition: 'the bundle of knowledge, attributes and capacities that can be learnt, that enable individuals to successfully and consistently perform an activity or task, and that can be built upon and extend through learning' (OECD, 2012). The concepts of 'skill' and 'competence' are used interchangeably. This definition creates a shift from traditional proxies of skills, such as formal education or diplomas and qualifications, to a much broader perspective in which the skills that people 
acquire, use, maintain and also lose over the course of a lifetime are included.

In the World Economic Forum's report, The Future of Jobs (2016), it is stated that the shelf life of people's skillsets is being threatened and possibly outdated by disruptive technologies and socio-economic forces. Hence, skills upgrading and (re)training for the existing and forthcoming workforce is crucial and at the heart of a (regional) skills policy. According to this, the core ambition of the House of Skills-project is to better anticipate and proactively manage the current realignments and transitions of the labour market by focusing on skills, as a more precise and detailed entry for recruitment and (intersectoral) career mobility. The central argument for this focus on skills is that not occupations or jobs, as a whole, become obsolete; technology always affects specific tasks of workers, that may disappear, change or emerge. Skills are directly linked with tasks, because they are the prerequisites for the competent performance of these tasks. Conceived in this way, skills are predominantly characteristics of individuals. In other words: the dynamic and disruptive character of the modern labour market is most visible and apparent on the level of tasks (on the demand or job/occupational/employer-side) and skills (on the supply- or workers/student/jobseeker-side). Promising job and career options for employees and jobseekers can be determined more adequate, efficiently and relatively simple when assessed on this micro-level of tasks and skills (World Economic Forum, 2019).

In the project of House of Skills, a specific set of pilots, related to skills mismatch, aims to innovate the matching routines of partners in the network by searching for and experimenting with a digital and data-driven skills- or competency-based approach. The way the labour market is organized nowadays is strongly influenced by the rapidly changing possibilities of online recruitment tools, such as online job platforms (e.g. Career Builder, LinkedIn) and the role of social media (Kettunen, 2017). 
Job matching is increasingly happening online. Not only does job matching provide jobseekers with a wide range of relevant opportunities, it also helps employees to identify new career paths and understand which transferable skills they possess that enhance mobility between occupations and even sectors. On the demand side of the labour market new database technologies and the use of algorithms can make online job matching relatively simple. Big data analysis of job vacancies and CVs allows employers and policy makers to detect and anticipate new emerging skills, mismatches and gaps, both on an intrasectoral and an intersectoral level. In short, digital technologies help to optimize the match between people and jobs and to indicate specific gaps between the actual and desirable situation in a person's career.

\section{SEARCH FOR ADAPTIVE MATCHING SYSTEMS AND TOOLS}

The search for an appropriate system of skills anticipation and matching within the context of House of Skills is driven by a wish to develop or adopt a skills framework that ideally meets the following criteria:

- it is derived from an overarching and stable (national) skills strategy and contributes to the integration of policy instruments from the various policy fields represented by the partners of House of Skills;

- it connects the world of work and the world of learning and education, which means that work-related skills and education-related qualifications can be aligned and matched;

- the framework helps to recognize, assess and validate nonformal and informal learning, for example from refugees or migrants;

- it also enables career guidance and employment professionals to help individuals (jobseekers, student, adults) to discover career opportunities; 
- the (occupational) taxonomy on which the matching is based offers the possibility of working with skills as one of the core matching components.

From the perspective of career guidance and employment counseling, the latter element of a suitable (occupational) taxonomy is an important and decisive criterion for a skills-based matching component (European Commission, 2014; Attwell \& Hughes, 2019) and has therefore been explored in more detail in the House of Skills-initiative. Matching persons with jobs and careers presupposes commensurate variables on both sides of the matching process. In career guidance and organizational behavior research, Person-Environment Fit is most commonly conceived and measured as the similarity between characteristics of the person on the one side (interests, values, beliefs, aptitudes) and of the work environment on the other side (occupation, job, organization, culture). When we narrow down the matching process by focusing merely on skills and competences, we will need an (occupational) taxonomy that enables commensurability on this skills component: only then a (good or bad) fit and proximity between a person and a job can be determined or measured. The challenging shift from a static matching approach to a more dynamic way of matching has led to many new taxonomies and approaches (Borbély-Pecze, 2019). We will explore two interesting and promising ways of working with occupational taxonomies in skills- and competence-based matching.

First of all, an inspiring example of an application of an occupational taxonomy used for skills-based matching can be found in Towards a Reskilling Revolution, a report from the World Economic Forum (2016). It describes a practical and experimental approach to identify and systematically map out stable job opportunities for workers who face declining job prospects. In this study, jobs are being broken down into a series of relevant and measurable components, including skills, in order to compare and 
match them with other (target) jobs. The occupational taxonomy used in this approach is the Occupational Information Network ( $\mathrm{O}^{*} \mathrm{NET}$ ) database, the most prominent source of occupational information in the United States; it describes the skills, knowledge, abilities, education, training, and experience required to perform a job. Based on a data-driven approach, parameters are operationalized for viable and desirable job transition options throughout the current and future labour market. The 'job-fit' of an individual worker and the 'job similarity' of a target job can thus be calculated on the basis of objective and realistic criteria. This innovative approach illustrates the power of digital data in labour market policy and has the potential to help individuals, employers and policy-makers in mapping out job transition pathways and reskilling opportunities.

A second interesting development in the realm of new taxonomies is ESCO, a classification of European Skills, Competences, Qualifications and Occupations, available in 26 European languages (ESCO, 2015). As a multilingual digital tool, ESCO is a skills-based system for the matching of skills and jobs and is linked to other European and international standards and qualifications. It connects employment to education by providing a uniform vocabulary as common ground for both sides of the matching process. This taxonomy 'deconstructs' every occupation into skills, competences and qualifications (e.g. ESCO has a classification of 13,000 skills). In ESCO the core element of the matching process is no longer the person or the occupation as a whole. The focus of the matching process is on the level of separate skills, competences and qualifications. This enables matching systems and tools to map a jobseeker's knowledge, skills and competences in more detail, based on his biography and career. By using these smaller components in algorithms, ESCO helps to create a more precise, idiosyncratic and less standardized picture of the skills and competences of an individual. As a result, a person can find the (crafted) jobs or sets of tasks that best match his or her unique 
set of skills and employers can optimize the identification of the talents they need.

\section{BUILDING A MATCHING SYSTEM: VIABLE EXAMPLES}

The search for matching tools on the basis of skills or competences has inspired various labour market institutions to experiment with concrete services and tools. Several countries have successfully implemented diverse applications of skills matching. Sweden for example, has developed 'Jobskills' as a digital matching tool for asylum seekers: job seekers can provide extra information on the specific skills they acquired in formal and informal settings (Joyce, 2018).

In various reports on skills anticipation and matching (e.g. Cedefop, 2015) the Flemish Public Employment Service (VDAB) is praised because of its innovative and comprehensive approach on career guidance and employment counseling on a skills basis. As a frontrunner in Europe, the VDAB has launched since 2010 a set of services based on competences as the reference framework for labour market interventions, called 'Competent'. The skills taxonomy used in these services as a central building block, is an adaptation of the ROME 3 standard from the French Public Employment Service, Pôle Emploi (Leroy \& Struyven , 2014). The skills sets used in Competent have been validated by the social partners, who delivered the input for the occupational profiles and required skills in the different sectors of the labour market and are engaged in the maintenance of the content of the matching system.

This type of 'fine-grained matching' the VDAB has designed (Leroy, 2017) creates benefits for jobseekers and employers alike. Not having a certain diploma or (formal) qualification does not automatically exclude a candidate from a job or vacancy. Vacancies and job options are considered potentially relevant 
for a candidate when he or she has a minimum match of $50 \%$ of the required competences. On the other hand, the system includes prior/elsewhere or otherwise acquired competences in the job search process. Thirdly, a more detailed analysis of the skills gap of a jobseeker concerning a target job can be addressed and applied to shorten the path towards overcoming that gap.

Three key success factors can be distinguished in the Flemish approach (Cedefop, 2015):

- The usability and simplicity for the end user; e.g. when a jobseeker creates a user profile by indicating his professional experience the web application automatically lists the skills linked to these positions and allows for personalizing and adapting this skills profile.

- The practical application of the skills matching approach and the collaboration with relevant stakeholders; this illustrates that a broader policy framework can increase coherence and integration in different areas of the labour market.

- The possible link with private sector vacancy databases: the database is accessible through API (application programming interface) and is linked to international occupational standards (e.g. ESCO).

\section{DISCUSSION}

Skills anticipation and matching has gained momentum in recent years. Impetus has come from rapid technological and economical changes in labour markets. This dynamism affects occupations and jobs partially, on the level of separate tasks. As a result, tasks and sets of tasks change, emerge or disappear and jobs and occupational profiles will increasingly vary and differentiate, highly dependent on specific contextual factors. Skills or competences, as personal prerequisites for the performance of tasks, become more important. 
This explains why the labour market policy of the regional network of the House of Skills in Amsterdam is attuned to these microdynamics of work and careers. In this initiative, it is assumed that matching people with jobs can and should be operationalized in a more detailed, granular and refined way, powered by the advanced possibilities of digital and data-driven technologies. Recent occupational taxonomies, like ESCO and O'NET are inspirational and look like a promising way ahead. Various countries have designed experimental settings and effective matching tools with skills or competences as the main proxy. The P-E fit or matching theories can be renovated, given these more liquid and flexible applications and services. Their relevance for careers practice and guidance professionals has been renewed and updated.

Matching and P-E fit are contested concepts. The critics are right when they state that in career guidance more -and differentfactors play a role than competencies, skills and diplomas alone. Next to that, the profession of career guidance should be aware that it will not adjust or adhere solely to the economic paradigm of 'the efficiency model', in which the main concern seems to be a smoother relationship between supply and demand (Sultana, 2017). Thirdly, tightly connected to this, there is a realistic danger that with increasing sophistication of automation and Artificial Intelligence used in job matching, the need for human forms of careers advice and guidance is underestimated or played down. And of course, as Attwell and Hughes (2019) argue, with algorithms being applied in career guidance, it is necessary to ensure that machine-generated outcomes and instruments are as fair and unbiased as possible.

But we should not throw the baby out with the bathwater (Reid, 2016). As the type of skills needed in the labour market change rapidly, workers and job-seekers will have to engage in life-long learning if they are to remain not just employable but also seek fulfilling careers. Why not, keeping in mind the criti- 
cal conditions for successful implementation mentioned above, try to enrich the matching process? We can carefully explore the possibilities of modern data technology and add measures for job and career satisfaction or organizational climate, because we, as career specialists, agree that these are relevant factors too. That could be a strong field for further research.

In the meantime, labour markets change rapidly, and both employees and employers seek help. Mitchel and Krumboltz, prominent criticasters of the matching theories in the domain of career guidance, have provocatively stated: 'Trying to place an evolving person into the changing work environment... is like trying to hit a butterfly with a boomerang' (1996, p.263). Nicely put, but in times of high volatility and fluidity of many occupational environments the main challenge of career guidance might be to keep on trying!

\section{REFERENCES}

Attwell, G., \& Hughes, D. (2019). Learning about careers: Open data and labour market intelligence. RIED. Revista Iberoamericana de Educación a Distancia, 21(2), 81-106.

Bauman, Z. (2000). Liquid Modernity. Cambridge: Polity Press.

Bimrose, J. (n.d.). Traditional theories, recent developments and critiques. Coventry: University of Warwick, Institute for Employment Research (IER). Retrieved from https://warwick.ac.uk/fac/soc/ier/ngrf/effectiveguidance/improvingpractice/theory/traditional/

Borbély-Pecze, T. B. (2019). The changing relationship between people and their job - The validity of career information. British Journal of Guidance and Counselling. https://doi.org/10.1080/03069885.2019.1621264

Cedefop (2015). Tackling unemployment while addressing skill mismatch. Lessons from policy and practice in European Union Countries. Luxembourg: Publications Office.

Cedefop (2016). Labour market information and guidance. Luxembourg: Publications Office. 
Dierdorff, E.C., \& Morgeson, F.P. (2007). Consensus in work role requirements: The influence of discrete occupational context on role expectations. Journal of Applied Psychology, 92, 1228-1241.

Edwards, J. R. (2008). Person-environment fit in organizations: An assessment of theoretical progress. The Academy of Management Annals, 2, 167-230.

ESCO (2015) Strategic framework. Vision, mission, position, added value and guiding principles. Brussels. Retrieved from https://ec.europa.eu/esco/portal/home Frese, M., \& Fay, D. (2001). Personal initiative: An active performance concept for work in the 21st century. Research in Organizational Behavior, 23, 133-187.

Grant, A. M., \& Parker, S. K. (2009). Redesigning work design theories: The rise of relational and proactive perspectives. The Academy of Management Annals, 3, 317-375.

Hall, T., \& Les Heiras, M. (2007). Reintegrating job design and career theory: creating not just good jobs, but smart jobs. Journal of Organizational Behavior, $31,448-462$.

Hartung, P. (2005). Integrated career assessment and counseling: mindsets, models and methods. In W. B. Walsh \& M.L. Savickas, Handbook of vocational psychology. New Jersey: Lawrence Erlbaum Associates.

Inkson, K., Dries, N., \& Arnold, J. (2015). Understanding Careers. Los Angeles, CA: Sage.

Jansen, K. J. and Shipp, A. J. (2018). Fitting as a temporal sensemaking process: Shifting trajectories and stable themes. Human Relations. https://doi. org $/ 10.1177 / 0018726718794268$

Joyce, P. (2018). Integration after 2015. What can Sweden learn from Germany? (Working paper). Stockholm: Ratio Institute.

Kettunen, J. (2017). Career practioners' conceptions of social media and competency for social media in career services (Doctoral dissertation). Jyväskylä: Finnish Institute of Educational Research. Retrieved from https://jyx.jyu.fi/bitstream/ handle/123456789/55367/978-951-39-7160-1.pdf

Kristof-Brown A., Zimmerman R., \& Johnson E. (2005). Consequences of individuals' fit at work: A meta-analysis of person-job, person-organization, person-group, and person-supervisor fit. Personnel Psychology, 58(2), 281-342.

Leroy, F. (2017). Competence-based matching: the holy grail? In Managing Workforce potential. A 20/20 vision on the future of Employment Services. Utrecht: WCC Group. Retrieved from: https://www.wcc-group.com/managingworkforcepotential.pdf

Leroy, F., \& Struyven, L. (2014). Building bridges, shaping the future of public employment services towards 2020. die Keure, Brussels. 
NICE (2016). Memorandum on Academic Training and Research in Career Guidance and Counselling. In Schiersmann, C., Einarsdóttir, S., Katsarov, J., Lerkkanen, J., Mulvey, R., Pouyaud, J., Pukelis, K., Weber, P., (Eds), European Competence Standards for the Academic Training of Career Practitioners. NICE Handbook Volume II. Opladen: Barbara Budrich.

Maree, K. (Eds). (2017). Psychology of career adaptability, employability and resilience. Cham: Springer.

Mitchell, K., \& Krumboltz, J. (1996). Krumboltz's learning theory of career choice and development. In D. Brown \& L. Brooks (Eds.), Career choice and development (3rd ed.). San Francisco, CA: Jossey-Bass.

Mittendorff, K., Faber, M., \& Staman, L. (2017). A matching activity when entering higher education: Ongoing guidance for the students or efficiency instrument for the school? British journal of guidance $\mathcal{E}$ counseling, 45(4), 376390.

Moore, C., Gunz, H., \& Hall, D.T. (2007). Tracing the historical roots of career theory in management and organizational studies. In H. Gunz \& M. Peiperl, Handbook of Career Studies. Los Angeles, CA: Sage.

OECD (2012). Better Skills, Better Jobs, Better Lives: A strategic approach to skills policies. OECD Publishing, Paris.

Parsons, F. (1909). Choosing a vocation. Boston. MA: Houghton Mifflin.

Reid, H. (2016). Introduction to career counseling \& coaching. Los Angeles: Sage.

Savickas, M.L. (1997). Career adaptability. An integrative construct for life-span, life-space theory. Career Development Quarterly, 45, 247-259.

Sanders, J. (2016). Sustaining the employability of the low skilled worker: development, mobility and work design. Dissertation. Maastricht: Research Centre for Education and the labour market.

Schmid, G. (1998). Transitional labour markets: A new European employment strategy (Discussion Paper) / Wissemschaftszentrum Berlin für Sozialforschung, Forschungsschwerpunkt Arbeitsmarkt und Beschäftigung, Abteilung Arbeitsmarktpolitik und Beschäftigung, 98-206. Berlin: Wissenschaftszentrum Berlin für Sozialforschung gGmbH.

Su, R., Murdock, C., \& Rounds, J. (2015). Person-Environment Fit. In P. J. Hartung, M.L. Savickas \& W.B. Walsh, APA Handbook of Career Intervention, Vol. 1. Foundations. Washington: American Psychological Association.

Sultana, R. (2018). Precarity, austerity and the social contract in a liquid world: career guidance mediating the citizen and the state. In T. Hooley, R.G. Sultana, \& R. Thomsen, Career guidance for social justice. Contesting neoliberalism. New York, NY: Routledge. 
Sylva, H., Mol, S.T., Den Hartog, D.N., \& Dorenbosch, L. (2019). Person-job fit and proactive career behaviour: a dynamic approach, European Journal of Work and Organizational Psychology. https://doi.org/10.1080/135943 2X.2019.1580309

Vos, de. A., \& Heijden, B. van der (2015). Handbook of research on sustainable careers. Cheltenham: Edward Elgar Publishing.

World Economic Forum (2016). Towards a reskilling revolution. A Future of jobs for all. Geneva: Author.

World Economic Forum (2016). The Future of Jobs. Employment, skills and the workforce strategy for the Fourth Industrial Revolution. Geneva: Author.

World Economic Forum (2019). Strategy for the new economy. Skills as the currency of the new labour market. Geneva: Author. 